\title{
Multicultural Education as Subtext
}

\author{
Kip Téllez \\ University of California, Santa Cruz
}

For many children and youth, United States schools are tantamount to skill factories, serving only to impart dreary and meaningless facts. This condition is especially true for low-income students of color, for whom schooling often fails to capture any measure of imagination and turns learning into brutal, boring ritual. In an era of accountability, when standardized test scores are tracked like mutual funds and teachers are put under increasing pressure to improve their school's ranking, an engaging curriculum is unlikely for any student. Children of color can expect the boredom provoked by an education designed for accountability (in favor of genuine learning), but they also face humiliation, a condition much worse than mere boredom. Avishair Margalit (1996) suggests that a "decent society is one whose institutions do not humiliate people" (p. 1). Multicultural education, in its widest goals, should eliminate humiliation and imbue honor and self-respect among all children and youth; it should, after all, inspire. In my view, the first responsibility of the school as an institution must be to avoid humiliation.

In this article, I argue that our current attempts to enhance the educational experience of children of color are faulty at best and sometimes humiliating. By relying on one popular strategy, we may try to meet the needs of marginalized youth by focusing on appropriate teaching practice alone, an approach adopted by those who pay attention to learning styles. Such a focus does not necessarily lead to humiliation but is largely ineffective. More pernicious are two sources of humiliation in multicultural education. One route to humiliation takes students along for a superficial and truncated walk through their cultural heritage. This type of multicultural education has been called the "heroes and holidays" approach and is most closely associated with the shortcomings of Black History month. I won't expand further on this source of humiliation because I believe many other thoughtful educators have been very convincing in their arguments against the merely "additive" approach. A second route to humiliation, although much less common, loads the formal curriculum with deeply held cultural traditions and beliefs, and then puts this curriculum

Requests for reprints should be sent to Kip Téllez, Crown College 229, 1156 High Street, Santa Cruz, CA 95064. E-mail:

ktellez@cats.ucsc.edu in the hands of teachers with little understanding of the cultures they are teaching about. As this curriculum moves through students' lives, teachers, perhaps unwittingly, transform important community and cultural knowledge into tedium; such a curriculum mutates a culture's valued wisdom into dreary reading passages designed for "comprehension." Yet this is the kind of curriculum that many educators believe is needed to liberate children of color from the cage of underperformance. Taking a position against this effort is the chief purpose of my article.

\section{"Multicultural education, in its widest goals, should eliminate humiliation and imbue honor and self-respect among all children and youth; it should, after all, in- spire. In my view, the first re- sponsibility of the school as an institution must be to avoid hu- miliation."}

As educators who care deeply about the experiences of children and youth of color, we should work hard so that schools honor and dignify all students. I am confident that those who promote multicultural education in the general curriculum share this vision. However, I argue that multicultural education should not necessarily be part of the formalized materials of the school because including such knowledge in the general curricular space can be humiliating. Consequently, I am suggesting that the most inspired and even useful multicultural education is one that conducts its work outside the boundaries of the prescribed curriculum, at the level of subtext.

I came to this idea studying Mexican American student teachers placed in classrooms composed largely of Mexican-American children (Téllez, 1999). I had hoped to find that the student teachers were altering the curriculum by using their ethnic knowledge, but they found the elemen- 
tary school curriculum impenetrable and consequently discovered other ways to "connect" with their students. The student teachers I interviewed helped me to realize that I had done the same thing as a beginning teacher. We all made efforts to create cultural linkages with our students in ways that had nothing to do with the school's formal objectives, but nevertheless encouraged our students to do well in their academic work. For instance, one of the student teachers I interviewed began an ongoing conversation about Mexican and Mexican American boxers with one of the more "challenging" boys in her student teaching class. Not surprisingly, she found no reading selections about Mexican boxers in the adopted textbook; nor were any books on the subject available in the library. However, she understood the importance of boxing in Mexican and Mexican American culture, especially among boys and men, and knew that by sharing what she knew about heroes such as Oscar de la Hoya or Julio Cesar Chavez, she could make his schooling a more coherent experience for this boy. She used her conversations to build connections to other readings and ideas in the standard curriculum, recommending that he use boxing as a theme for his journal writing.

\section{"The more culturally relevant the knowledge, the less likely it is that these teachers will under- stand it. However, I argue the more likely that such knowledge will be used to humiliate."}

In my own experience I found that talking with students about the values and knowledge we shared had a very special purpose, one that both motivated the students and served to connect us to the formal curriculum, without necessarily altering it. More important, this discourse never disrespected our shared cultural knowledge. I suggest that such informal discussions and connections are legitimate multicultural education.

I will begin by discussing two problems with multicultural education, both of which have convinced me that we abandon our current attempts to alter schooling for children and youth of color in favor of one that sees multicultural education as subtext.

\section{The Canon Is Not the Place}

The common curriculum (e.g., the school textbooks) has been attacked from many perspectives, and not just for failing children of color. Written by committees, worked over by elected officials (all of whom have their specific interests), and influenced by a myriad of special interests (from the Christian Coalition to the National Organization for Women), the formal curriculum is rendered uninspired at best. Indeed, the prescribed curriculum fails, in varying degrees, all children and youth, not just those of color. In spite of the mandated curriculum, the best teachers find capable and clever ways around the sanctioned curriculum, and many even use its weaknesses to create solidarity between themselves and their students. By pointing out the dreariness of the textbook, a feature most students immediately recognize, many teachers will use their own lessons to connect their students to the overarching goals of the public school without succumbing to the adopted text.

The teacher who builds custom lessons has mastered the ability to use the informal spaces of school life (e.g., recess, after school, chatting with parents) to understand the students' interests. By understanding the deeper cultural values of students, the thoughtful teacher uses this knowledge in the creation of the customized curriculum. The teacher who does not take the time to understand his or her students will fail to develop a curriculum that understands them. Teachers who forego the opportunity to understand students' lives are more likely to use the textbooks and other formalized curricula. This is the chief obstacle when placing specific cultural knowledge in the curriculum. If we place multicultural curriculum in the textbooks, for instance, what do we expect such teachers to do with it? The more culturally relevant the knowledge, the less likely it is that these teachers will understand it. However, I argue the more likely that such knowledge will be used to humiliate. The following example, I hope, will demonstrate that the canon is not the place for the sacred.

Carmen Lomas Garza grew up in south Texas and, inspired by her mother's creativity, she began to paint powerful images of her childhood. As she gained notoriety as an artist, she published some of her paintings in a short book, simply titled Family Pictures (1999). Along with her paintings, she wrote a short narrative, published in both in English and Spanish, describing what the painting meant to her. Like many Mexican American teachers, I have had great success sharing this book with Mexican American children in schools. Her more recent book, In My Family, has been similarly received. The selection reproduced here, I maintain, represents the kind of text and image many would hope be included as part of the formal curriculum.

Healer

This is a scene at a neighbor's house. The lady in bed was very sick with the flu. She had already been to a regular doctor and had gotten prescription drugs for 


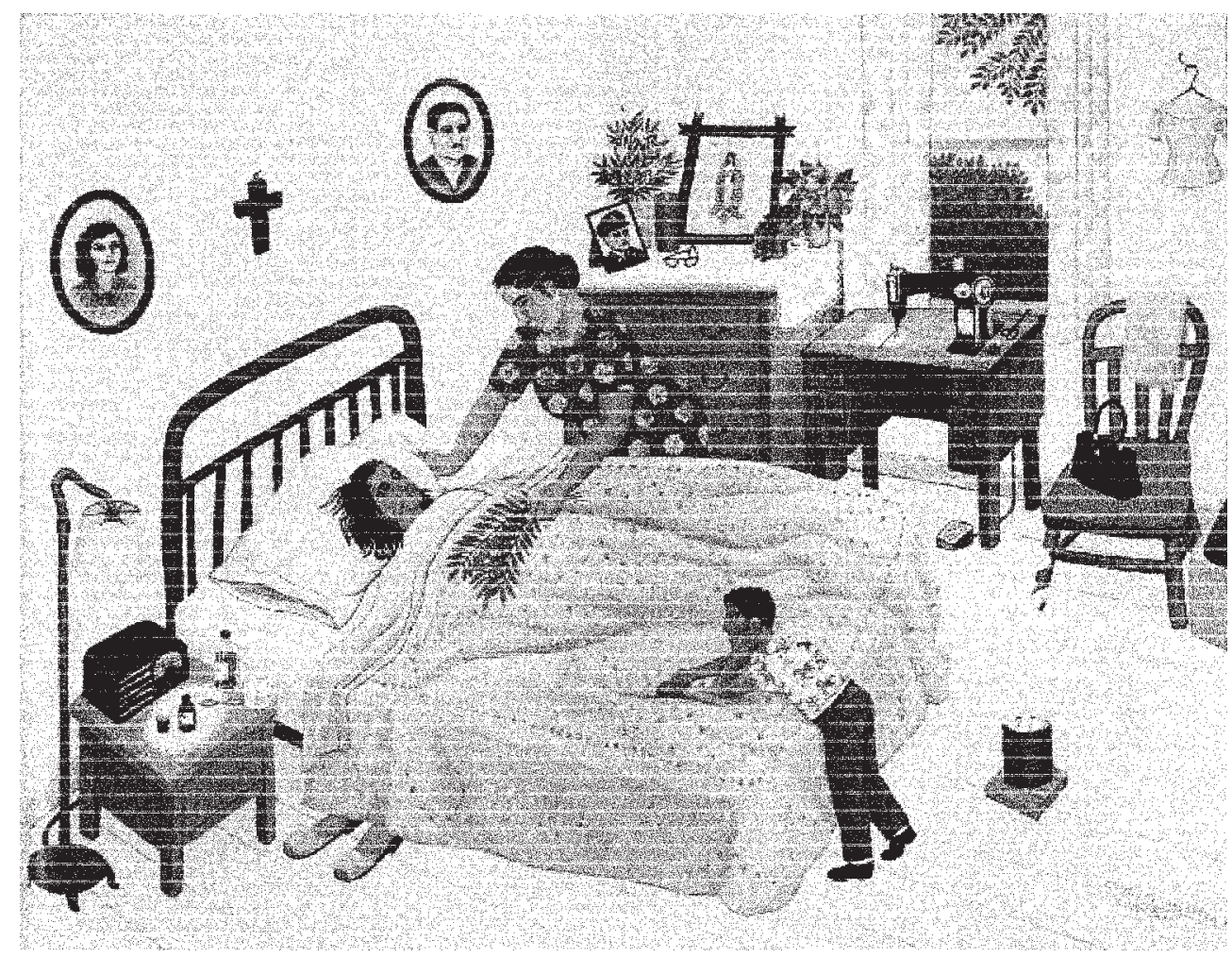

Figure 1. Painting by Mexican American Carmen Lomas Garza, representing type of curriculum many advocates of multicultural education would like to place in the formal school curriculum. From Family Pictures, by C. L. Garza, 1990, San Francisco: Children's Book Press. Copyright 1990 by Carmen Lomas Garza. Reprinted with permission.

her chest cold. But she had also asked a healer, a curandera, to do a final cleansing or healing for this flu. So the curandera came over and did a cleansing using branches from the rue tree. She also burned copal incense in a coffee can at the foot of the bed. Curanderas know a lot about healing. They are very highly respected.

\section{Curandera}

Ésta es una escena en la casa de una vecina. La mujer que está en cama estaba muy enferma con influenza. Ya había visto a un doctor y había conseguido una receta médica para sus pulmones. Pero también le había pedido a una curandera que le hiciera una limpieza final o cura para su enfermedad. Así que la curandera vino e hizo una limpieza usando ramas de ruda. También quemó incienso de copal en una lata de café al pie de la cama. Las curanderas saben mucho y ayudan mucho a la gente. Por eso se las respeta tanto.

"Curandera" represents a complicated piece of Mexican and Mexican American life. Healers such as the women Lomas Garza portrays remain a powerful ally in the lives of many Mexican Americans, and so-called folk remedies are common among Latinos in the southwestern United States (see Figure 1). Local "herbarias" (a store for herbs, candles, and other remedies) are part of daily life in many Latino neighborhoods. Understanding the modern role of the curandera, however, when many, though certainly not all, have access to contemporary medical treatments, is very complicated. And teachers who fail to understand the subtext, or deeper cultural knowledge, of the passage are likely to devalue it, thereby humiliating students. It is not difficult to imagine a middle-class, White teacher telling students, "This curandera stuff is interesting, but, really, make sure your mom takes you to the doctor if you are sick." This comment is entirely predictable from a teacher whose cultural heritage places great faith in medical science. Of course, the teacher is not necessarily giving bad advice-Lomas Garza is careful to make a similar suggestion. But the students in this teacher's class, however, may only hear derision in the remark. Or they may want to talk more about curanderas, while the teacher redirects the discussion to a new topic, one more familiar to his or her cultural knowledge. In this case, it is easy to see how the students, who view curanderas as a special part of their lives, could be humiliated.

The problem of putting deeply cultural knowledge in the formal curriculum is that when we allow-or en- 
force_cultural "products" to be taught by people who fail to understand the subtext of our culture, we can be almost certain that our most sacred knowledge will be turned profane.

\section{Emphasizing Good Practice Is Not Enough}

Ladson-Billing's (1994) successful work, The Dreamkeepers, has served to inspire many teachers and even more teachers-to-be. Her book deserves great praise for helping many teachers understand how exemplary African American teachers conduct their work. Ladson-Billings, as most readers already know, argued that successful African American teachers are distinguished by several attitudes and beliefs that are realized in their work with students. The focus of her work is on how such teachers achieve their success. By her own admission, she does not set out to determine what to teach, but rather focuses her work on teaching practice. I agree that strong teaching practice is important when working with low-income children of color, but the content of the school curriculum is perhaps more important. Further, I have wondered if a focus on teaching practice fails to point out what is, in fact, different, or at least differentially important, when teaching children of color. For instance, do the practices needed for school success among African American children apply equally to all quality learning endeavors, irrespective of the context? Ladson-Billings suggests that teachers who engage in culturally relevant practices view teaching as "digging knowledge out" of students. It is easy to see that this perspective must apply when working with African American children, but it might also apply to all children. I found a source, quite different in context and purpose than Ladson-Billings' book, that recommends a similar perspective. In Muriel Sparks' (1961) novel, The Prime of Ms. Jean Brodie, a wonderful and heartbreaking story about a Scottish teacher and her boarding school students (all girls), Ms. Brodie points out differences in beliefs between herself and the headmistress, who wants to meet with her.

I have no doubt that Miss Mackay wishes to question my methods of instruction. It has happened before. It will happen again. Meanwhile, I follow my principles of education and give of my best in my prime. The word education comes from the root $e$ from $e x$, out, and duco, I lead. It means a leading out. To me education is leading out of what is already in the pupil's soul. To Miss Mackay it is a putting in of something that is not there, and that is not what I call education, I call it intrusion, from the Latin root prefix in meaning in and term trudo, I thrust. Miss Mackay's method is to thrust a lot of information into the pupil's head; mine is a leading out of knowledge, and that is true education as is proved by the root meaning. (pp. 54-55)

Spark's thoughtful, albeit flippantly expressed, idea was made in an era when there was virtually no regard for cultural diversity. Could such an attitude, then, be important for any teacher, not just those who work with African American students? Indeed, the very reason why European-American middle and upper class experience greater success in school is because their culturally similar teachers "dig knowledge out" of their students. However, in this context, the teacher, because he or she shares the culture of the students, need not "dig" too deeply to find a subtext that serves to connect them to the wider goals of schooling. Their commonality makes building on their abiding cultural knowledge an easy task, a task made much more difficult when the teacher does not share the cultural knowledge of the students.

Consequently, I do not believe that focusing on practice alone will significantly improve on the education of children and youth of color. It could be argued that the digging Ladson-Billing and Sparks advocate could serve as the source of curriculum as subtext, the kind of which I am suggesting. Perhaps, but I don't think that digging is the appropriate metaphor for curriculum as subtext. Indeed, I think no metaphor is needed: Teachers should simply listen to their students and the community talk about their lives, and then build on what they have learned.

The curriculum must play an important role, but there is great danger when culturally important knowledge is placed in the formal materials of the school. However, moving cultural knowledge out of the sanctioned school materials is risky as well. What remains is multicultural education at the margins, at the level of subtext.

\section{Curriculum as Subtext}

Modern critical theorists have typically portrayed the hidden curriculum as an instrument of oppression and humiliation. But as Hlebowitsh (1994) points out, the hidden curriculum has not always been thought of as negative. The hidden curriculum can serve as a point of solidarity between teachers and students. It can be the source of "teachable moments" when teachers and students find a common interest and follow it. When we conceive of multicultural education as subtext, we no longer need to battle with proponents of the "canon," but we may find ourselves in a more difficult fight, one that asks us to consider our deepest, most precious cultural knowledge and whether that knowledge belongs in the school, in the hands of teachers who don't understand it.

Michelle Foster (1995) suggests that cultural unity among teachers and students can be "implicit and unspo- 
ken." Her point has inspired me to think more deeply about our aims and purposes in multicultural education. Perhaps the formal curriculum should not shelter our culture's knowledge. Is it possible that some cultural knowledge is best shared in informal, casual, and more intimate settings, when the pressure of formal teaching and, more importantly, formal testing is absent? If we fight to include our most precious cultural knowledge in the canon, it is only a matter of time until such knowledge is fodder for the passages on standardized tests. For my own part, it would hurt my spirit to find a Stanford Achievement Test passage on curanderas.

In the end, teachers themselves must decide when and how to diversify the curriculum, based on their intimacy with the valued cultural knowledge-the sacred knowledge-held by students and their communities. Teachers must face squarely their limitations and consider the effects of working with specific and deeply held cultural knowledge. Will students view their culture as being stolen or co-opted? Will parents view such curriculum similarly? Will formalizing the curriculum trivialize or humiliate? A teacher who has neither a knowledge of nor interest in curanderas, for example, should not be encouraged to teach about them.

I admit that the idea of putting the curriculum in the hands of teachers will sound preposterous to some. They'll argue that allowing teachers to decide the curriculum is the very source of our current problems. However, I would rather that White teachers help Mexican American children understand White culture than humiliate them by mishandling their intimate knowledge and beliefs.

However, this recommendation does not suggest a passive role for thoughtful educators. First, we must recruit more teachers of color into the profession, a task much more difficult than it sounds. If we can be successful in our recruiting efforts, we must help teachers of color to understand the inadequacies of the formal curriculum and explore with them how they can incorporate what their community values most into their lessons. However, we will have to be more specific in explaining how to use cultural knowledge as subtext to the existing curriculum. In developing policy and practice in teacher preparation, we will need to move beyond the role model argument, beyond a vague desire to build a teaching force that shares ethnic proportions with the students; we must do better at explaining exactly how one develops multicultural curriculum by using the unstructured moments in schools.

Alongside recruitment of minorities and a more responsive teacher education for student teachers of color, we must run an equal effort to help middle and upper class, White preservice teachers commit to a vision of multicultural education. For most White teachers, their task is nothing short of learning a second culture. Some will understand the importance of the subtext of cultural knowledge in schooling and shoulder the task of learning culture. I fear that most won't, and in an era of teacher shortages, there will be great pressure to license those who don't see culture learning as the job of a teacher. However, as I have argued, asking such teachers to use a formal curriculum composed of deep cultural knowledge, which they will almost certainly misunderstand, will only serve to humiliate and further alienate our students of color.

If we are confused about the direction of multicultural education, it is only because we are working in unmapped terrain. Virtually all the fundamental works in education, from Dewey to Duckworth, have regarded the culture of teachers and students as a single flowing river, making its predictable path to the ocean. Such an assumption, I am certain, has served to humiliate many children of color. In spite of the challenges, we have made progress in sensitizing the larger educational community to our issues, but now, in the era of accountability, we are suffering under the weight of unprecedented demands on our teachers and students. The goal is nothing less than racial equality in academic achievement_-don't bother to ask about equal resources. Helping children of color erase the achievement gap will take new ideas that test what we believe about culture and education. Even the most energetic efforts at improving teaching practice or understanding "learning styles" will fall short. The curriculum must change, but the cultural knowledge of our children, sacred and precious, must never be used as a tool of humiliation.

\section{References}

Banks, J. A., \& Banks, C. A. (1989). Multicultural education: Issues and perspectives. Boston: Allyn \& Bacon.

Foster, M. (1995). African-American teachers and culturally relevant pedagogy. In J. Banks (Ed.), Handbook of research on multicultural education (pp. 570-581). NY: Macmillan

Hlebowitsh, P. S. (1994). The forgotten hidden curriculum. Journal of Curriculum and Supervision, 9, 339-349.

Ladson-Billings, G. (1994). The dreamkeepers: Successful teachers of African-American children. San Francisco: Jossey-Bass.

Lomas Garza, C. (1990). Family pictures = Cuadros de familia . San Francisco: Children's Book Press.

Margalit, A. (1996). The decent society. Cambridge, MA: Harvard. Spark, M. (1961). The prime of Miss Jean Brodie. London: Macmillan

Téllez, K. (1999). Mexican-American student teachers and the intransigency of the elementary school curriculum. Teaching and Teacher Education, 15, 555-570. 